odd to find no reference to the work of Keele and Armstrong in the section on cutaneous hyperalgesia, nor could any reference be found to Ridley's work on Meissner's corpuscles in man.

Clinicians will find much to interest them in this issue.

\section{System of Orthopaedics and Fractures (3th Edition)}

By A. Graham Apley. Pp. $x+477$, hard cover, illus-

trated. The Butterworth Group, Sevenoaks, 1977. £15.95.

This book deserves to be in its fifth edition. It provides a very clear and accurate account of the present day approach to the common problems of orthopaedic and traumatic surgery. To do this within the confines of 459 pages is no mean feat. This has been done by dividing the contents into three main sections, namely general orthopaedics, regional orthopaedics and injuries. Each part is tidily presented with short crisp sentences and generously illustrated with appropriate photographs and radiographs. It is right up-to-date with references even from 1977. The author who is well known for his talents as a teacher has produced a book which will remain popular amongst undergraduate and F.R.C.S. candidates for many years to come.

\title{
Notice
}

WORLD CONFERENCE ON CLINICAL PHARMACOLOGY AND THERAPEUTICS

London 3-9 August 1980

THE FIRST WORLD CONFERENCE ON CLINICAL PHARMACOLOGY AND THERAPEUTICS, under the sponsorship of the International Union of Pharmacology and the British Pharmacological Society, will take place in London in 1980.

Further information may be obtained from:

Conference Associates CPT.

34 Stanford Road,

London, W8 5PZ. 